\title{
Assistência psiquiátrica em Serra Pelada (PA)
}

\author{
Quirino Cordeiro Júnior ${ }^{1}$ \\ Márcio Bergamini Vieira ${ }^{2}$ \\ Carlos Eduardo Pereira Corbett ${ }^{3}$
}

No início da década de 1980, com a descoberta de ouro na região da Serra Pelada, localizada no sul do Pará, houve grande afluxo de pessoas para lá, com o intuito de tentar a sorte no garimpo. No fim da década, o garimpo foi fechado, porém muitas famílias permaneceram no local, dando origem à Vila de Serra Pelada.

Hoje, a Vila pertence ao município de Curionópolis (PA). O acesso da sede do município até ela é feito através de estrada pavimentada $(13 \mathrm{~km})$ e de terra $(35 \mathrm{~km})$, totalizando $48 \mathrm{~km}$, que são percorridos em cerca de uma hora e meia.

Com a desativação do garimpo, a principal atividade econômica da Vila foi extinta. Assim, a população que permaneceu no local vive em precárias condições socioeconômicas. A partir de março de 2002, foi implantado o Programa de Desenvolvimento Econômico e Social de Serra Pelada. O Programa apresenta atividades em quatro frentes, a saber, agropecuária, urbanismo, educação e saúde. O Projeto Saúde ocorre pela parceria entre a comunidade local e a Faculdade de Medicina da USP através da Fundação Faculdade de Medicina.

Após o trabalho inicial de reconhecimento, realizado na Vila de Serra Pelada pela equipe de saúde, que teve por objetivo traçar as diretrizes para a intervenção no local, as atividades assistenciais foram iniciadas, entre elas as de psiquiatria. O objetivo do grupo responsável pelo atendimento psiquiátrico era o de implantar a assistência na região, de acordo com as recomendações da Organização Mundial da Saúde para áreas como a da Vila, ou seja, proporcionar tratamento na atenção primária à saúde, garantir aos pacientes acesso gratuito aos psicotrópicos, garantir atenção psiquiátrica na comunidade e formar recursos humanos locais para a prestação do atendimento (OMS, 2001).

Assim, o início das atividades ocorreu com um treinamento para os agentes comunitários de saúde do município, com o objetivo de prepará-los para o reconhecimento de pacientes com transtornos psiquiátricos na comunidade. Na Vila, há 11 agentes de saúde, e cada um deles é responsável por cerca de 110 famílias (a população estimada é de 6 mil pessoas). Após esse treinamento, os agentes de saúde agendaram as consultas. O primeiro atendimento aos pacientes foi prestado por alunos da Faculdade de Medicina da Universidade de São Paulo (FMUSP), sob supervisão. O Projeto Saúde trabalha com alunos da FMUSP, com o intuito de oferecer a eles a oportunidade de treinamento em atendimento médico na atenção primária à saúde.

Nesse evento inicial foram atendidos 155 pacientes. Os transtornos mais comuns nessa população foram depressão (101: 65,16\%), transtornos ansiosos (34: $21,92 \%)$, deficiência mental $(14: 9,03 \%)$ e transtornos psicóticos (8: 5,15\%). Desses pacientes atendidos, 121 foram matriculados para acompanhamento. $\mathrm{O}$ fornecimento contínuo da medicação está

Psiquiatra pelo IPq HCFMUSP. Responsável pelo Programa de Assistência Psiquiátrica do Projeto Saúde do Programa de Desenvolvimento Econômico e Social de Serra Pelada.

2 Residente do IPq HCFMUSP. Membro do Programa de Assistência Psiquiátrica do Projeto Saúde do Programa de Desenvolvimento Econômico e Social de Serra Pelada.

Professor Associado da Faculdade de Medicina da Universidade de São Paulo. Coordenador do Projeto Saúde do Programa de Desenvolvimento Econômico e Social de Serra Pelada.

Endereço para correspondência:

Carlos Eduardo Pereira Corbett

Faculdade de Medicina da Universidade de São Paulo

Avenida Dr. Arnaldo, 455 - sala 1215

São Paulo, SP - CEP: 01246-903

Fone/fax: 3081-7799

E-mail: ccorbett@usp.br 
sendo viabilizado pela prefeitura de Curionópolis e pelo governo do Estado do Pará.

Após três meses de atendimento psiquiátrico na Vila, dos 121 pacientes matriculados para o acompanhamento ambulatorial, 116 estão aderidos ao tratamento, correspondendo a 95,86\% dos atendidos. A não aderência ao tratamento é um sério problema para os serviços psiquiátricos ambulatoriais (Campbell et al.,1991; Blackwell, 1992; Nicholson, 1994). Glyngdal et al. (2002), em pesquisa realizada em um centro de atendimento psiquiátrico ambulatorial em Copenhagen, mostraram que $32 \%$ dos pacientes não compareceram ao seu primeiro retorno, e que esse número caiu para $16 \%$ quando eles foram convocados para a próxima consulta. Chen (1991), em trabalho de revisão, mostrou que a não aderência ao atendimento psiquiátrico ambulatorial diminui quando os pacientes são contatados pelos serviços de saúde antes das consultas por meio de carta ou telefone. No caso da Vila de Serra Pelada, apesar de o Projeto ter apenas três meses de funcionamento, a aderência ao tratamento é boa. Tal resultado pode ser em decorrência da inclusão dos agentes comunitários de saúde no Projeto. Esses profissionais vão às casas dos pacientes para avisá-los e lembrá-los de suas consultas.

Não há médicos que residem na Vila de Serra Pelada. $\mathrm{O}$ atendimento médico à população local é prestado por médicos generalistas, que moram na sede do município. Esses profissionais estão recebendo treinamento através de seminários, cursos de reciclagem e supervisão dos casos atendidos, para que possam dar continuidade ao atendimento psiquiátrico à população. O objetivo final do Projeto Saúde é auxiliar o serviço público de saúde local a se capacitar para cuidar de maneira adequada de seus pacientes.

\section{Referências bibliográficas}

Blackwell, B. - Compliance. Psychother Psychosom 58(3-4): 1619, 1992.

Campbell, B.; Staley, D.; Matas, M. - Who Misses Appointments? An Empirical Analysis. Can J Psychiatry 36(3): 223-5, 1991.

Chen, A. - Noncompliance in Community Psychiatry: a Review of Clinical Interventions. Hosp Community Psychiatry 42(3): 282-7, 1991.

Glyngdal, P.; Sorensen, P.; Kistrup, K. - Non-compliance in Community Psychiatry: Failed Appointments in the Referral System to Psychiatric Outpatient Treatment. Nord J Psychiatry 56(2): 151-6, 2002.

Nicholson, I.R. - Factors Involved in Failure to Keep Initial Appointments with Mental Health Professionals. Hosp Community Psychiatry 45(3): 276-8, 1994.

Organização Mundial da SAúde - Relatório sobre a Saúde no Mundo 2001 (Saúde Mental: Nova Concepção, Nova Esperança). Gráfica Brasil, Brasília, 2001. 